\title{
PSYCHE
}

VOL. XXXIV.

APRIL 1927

No. 2

\section{THE THORACIC SCLERITES AND WING BASES OF THE ROACH PERIPLANETA AMERICANA AND THE BASAL STRUCTURES OF THE WINGS OF INSECTS}

By G. C. Crampton, Ph. D.

Massachusetts Agricultural College, Amherst, Mass.

The head and abdominal structures of the American roach have been described in Vol. 32, p. 195 of Psyche for 1925. In the present paper the thoracic sclerites and wing bases of the roach are discussed, and certain previously overlooked structures in the basal region of the wings of insects in general are described, since they appear to be of considerable interest from the standpoint of phylogeny and the interpretation of the wing veins

In examining the thoracic sclerites, it is preferable to study them in relation to the internal structures for muscle attachment, etc., and with this purpose in view, the dorsal (or the ventral) region of the thorax should be cut away, and the parts should be boiled in $10 \%$ caustic potash to remove the muscles and other soft parts, which may be washed away with a pipette. The parts should be studied immersed under water or alcohol, and the field of the binocular should be illuminated by a brilliant light provided with a bulls-eye condenser.

The neck ("cervicum" or eucervix) is a demarked anterior portion of the prothorax, whose membranous walls permit greater freedom of movement for the head. Its sclerites, called the cervical sclerites (cervicalia) are homologous with the intersegmental plates (intersegmentalia) occurring between the thoracic segments in certain Apterygota, and, according to their position, they are called the dorsal, lateral and ventral cervicals. 
The ventral cervicals pgu and is of Figs. 1 and 5 are narrow, transverse sclerites, homologous with the sclerites called the postgulare and intersternite by Crampton, 1926. The lateral cervicals $l c$ of Figs. 1 and 5, are the largest neck plates, and each is made up of three parts, or subdivisions. The anterior subdivision $e c$ bears a cephaliger $c g$ or process which articulates with the occipital condyles $o c c$ of the head. The median lateral cervical $i c$ touches its fellow of the opposite side in the median ventral line of the body, in the fashion characteristic of most roaches, mantids and termites. The posterior lateral cervical area $p o c$ is inflexed and bears a small internal protuberance at the point $f$ of Fig. 5 . The small sclerite $t$ of Figs. 1 and 5 may be included with the lateral or with the dorsal, cervicals. The dorsal cervicals $p r$ (Fig. 15) are small and unimportant, but the dorsal cervicals it are quite large and unite posteriorly to form a horse-shoe-shaped area bearing a pair of internal protuberances. The posterior dorsal cervicals (or postintertergites) bear the internal tendons et (Fig. 15) for muscle attachment.

The sternal region of each thoracic segment (excepting the metathorax) contains three typical sternites or sternal sclerites as follows. The basisternite $b s 1, b s 2$, and $b s 3$, of Fig. 1 , is the principal sternite and is usually connected with the episternal region es by a precoxal bridge $p c$. In the mesothorax and metathorax, the basisternum $b s 2$, and $b s 3$, of Fig. 1 is composed of an unpaired median portion and two lateral halves.

The furcasternite (or furca-bearing sternite) $f s 1$, is subtrapezoidal in the prothorax, but it is shaped like an inverted " $\mathrm{Y}$ " in the meso- and metathorax. The furcasternite $f_{s}$ (Fig. 1) bears the furcal pits, or furcacavæ $f p$, which are the external manifestations of the invaginations forming the internal diapophyses, or furca fu, of Fig. 5. These paired apophyses, or diapophyses (furca), serve to hold the nerve chain in place, and they furnish attachment for muscles etc. Miall and Denny in their book on the cockroach failed to find the prothoracic furca $f u$ of Fig. 5, but these structures are quite well developed in the prothorax, and are composed of a delicate shaft, or basifurca, and a broad distal portion, or distifurca, which extends to the apodeme $a p$ of the pleural region. 
The spinasternite ss of Figs. 1 and 5 is not very greatly elongated in the prothoracic region, but in the mesothorax it is long and slender. The spinasternite of the metathorax is atrophied, or it is indistinguishably united with the furcasternite $f s$, in this region. The spinasternite $s s$ of Fig. 1, bears the spinal pit, or spinacava $s p$, which is the external manifestation of the invagination forming the internal, median, unpaired apophysis called the monapophysis, or spina spi, of Fig. 5, which serves for muscle attachment etc.

The internal sternal processes, such as the furca $f u$ and spina spi, may be called the endosterna, and as was mentioned above, these endosterna serve tor the attachment of muscles etc. As was suggested by Crampton, 1918, instead of designating muscles by their function etc., it is preferable to designate them by their points of origin and insertion; and if this method be followed, we may speak of the furco-apophysal muscles, the furco-coxal muscles, furco-trochanteral muscles, etc., or the profurco-mesofurcal muscles, prospino-mesospinal muscles, etc., and the terms are self-explanatory.

In the three thoracic segments (Fig. 1) a pre-coxal bridge composed of the sclerites $p c$ and $a c$ connects the basisternite $b s$ with the episternum $e s$. The sclerite $p c$ is very loosely connected with the pleural region in the meso- and metathorax, and may possibly represent the sclerite called the lateropleurite, while the sclerite $a c$ which is well developed and is connected with the sternal region in the mseo- and metathorax, may represent the laterosternite; but provisionally, at least, I have followedthe interpretations indicated by the labelling, (see list of abbre viations) until the matter can be definitely determined.

In the meso- and metathorax, a ventral prolongation of of the suture $s$ (Fig. 1) demarks the preepisternum pes or anterior marginal sclerite, which bears an internal protuberance for muscle attachment. In front of this region is a "dimplelike" impress, or depression labelled $i$ in Fig. 1, which marks the location of an internal tumulus, or protuberance labelled $e n$ in Fig. 5, to which certain muscles are attached

An infolding (or "inpocketing") of the integument of the pleural region forms an internal ridge, or endopleuron $e p$ of Fig. 
5 , while the external lips of the fold meet to form the pleural suture $p s$ of Fig. 1, which demarks the epimeron $\mathrm{em}$ from the episternum es. At the ventral end of the pleural suture $p s$ of Fig. 1 , is the coxifer $c f$, or coxa-bearing process, while at the dorsal end of the pleural suture $p s$ is the alifer $o$, or pleural fulcrum of the wing. Internal processes of the coxifer labelled ecf 3 in Fig. 5, and internal processes of the alifer, labelled $e a 2$ in Fig. 5, are fairly well developed in the roach; and the endopleuron $e p$ of Fig. 5 gives off an apodeme, or process $a p$, rather closely associated with the furca $f u$.

In the meso- and metathorax, there occurs in front of the pleural suture $p s$ of Fig. 1, a suture $r$, which divides the episternal region es into an upper region aes, or anepisternite, and a lower region, or katepisternite (bearing the label es in Fig. 1). An anepisternal incision aei divides the anepisternite into an anterior and posterior region. The basalar sclerites $x$ and $u$, situated dorso-caudad of the anepisternal incision aei (Fig. 1), are portions of the pleural region. The anterior basalare $u$ of Fig. 1 is demarked by the suture $s$, and it bears an internal process $e b$ of Fig. 5. The posterior basalare $x$ of Fig. 1 is a detached portion of the pleural region in front of the alifer $o$, and both of the basalar sclerites are associated with the movements of the wing in flight.

Above the alifer $o$ of Fig. 1 is the intraalare $i a$ (See also Figs. 13 and 14), which is an alar ossicle connected with the dorsal alar ossicle $a$ of Fig. 16 (Compare also Figs. 13 and 14). The sclerite ia may be a detached portion of the wing structures, but it is hardly a detached portion of the pleural region. The subalare $s a$ of Fig. 1, however, may have been formed by the deposition of chitin in the membrane below the wing, for the attachment of the mero-subalar muscles extending between the meral region of the coxa and the subalar plate in question.

The trochantin, bearing the labels atn and ptn in Fig. 1, is a triangular plate in front of the coxa, and the trochantin bears at its tip an internal trochantinal tendon $t$ tn of Fig. 5, for muscle attachment. A trochantinal suture, with its corresponding internal ridge or endotrochantin etn of Fig. 5, divides the trochantin of the meso- and metathorax into an anterior region atn and a 
posterior region ptn (Fig. 1), while a transverse "break," or cleft, divides the prothoracic trochantin into a basal region btn and a distal region, $d t n$, as is also the case in other roaches, mantids and termites, etc. In such cases, the small distal region $d t n$ is usually interpreted as the entire prothoracic trochantin, althrough the basal portion btn also belongs to the prothoracic trochantin. The trochantin of all segments is closely associated with the pleural region (from which it is separated by the pleurotrochantinal suture $p$ of Figs. 1 and 5) and it may be a detached portion of the pleural plate. On the other hand, it is maintained by several investigators that the trochantin (or even portions of the pleural plate itself) is a detached basal region of the leg, to which the term subcoxa is sometimes applied.

Between the trochantin and the coxa is a small sclerite pac called the paracoxale, which bears an internal paracoxal tendon pat (Fig. 5) for muscle attachment. The sclerite pac is either a detached portion of the marginal region of the coxa, or it was formed in the membrane between the trochantin and coxa, to bear the internal tendon pat for muscle attachment. Behind the coxa is an internal tendon $p t$ (Fig. 5) called the postcoxal tendon, to which are attached certain muscles. A faint "impress" marks its location externally.

In the prothorax, a marginal region, the basicoxale $b c$ of Fig. 1 , is demarked in the basal region of the coxa. Its anterior region $\mathrm{cm}$ has been termed the coximarginale, and its posterior region $m e$ is homologous with the meron me of the other legs. An internal ridge, or endocoxa, demarks the region $b c$ internally, and serves for the attachment of muscles, as described by Dr. R. E. Snodgrass. In the meso- and metathorax, the meral region $m e 2$ and $m e 3$ is much more extensive than in the prothorax (i. e. me of Fig. 1), and a meral ridge, or endomeron $m r$ of Fig. 5, serves to demark the meral region internally-and it also serves as a ridge for muscle attachment. The parts of the leg of a roach, together with their tendons, method of articulation, etc., have been described in a paper by Crampton, 1923 (Can. Ent. $L V$, p. 126), and need not be further discussed here, since the appendages of the thorax will be described more fully in a paper dealing with the legs and wings of the roach. 
The spiracle $s t$ between the pro- and mesothorax (Figs. 1 and 5) is mesothoracic in origin, and should therefore be spoken of as the meso-thoracic spiracle, despite the fact that it is very closely associated with the prothoracic region. The second spiracle is metathoracic, and the third one is the first abdominal spiracle. The mesothoracic spiracle is usually located in the membranous region continuous with that containing the spinasternite ss (Figs. 1 and 5), particularly in larval forms, and this may indicate that the supposed prothoracic spinasternite is mesothoracic rather than prothoracic. In any case, this sternite may be referred to as the spinasternite, although if it belongs to the mesothorax (as its association with the spiracle in other insects seems to indicate) the term poststernellum, applied to it by some investigators, is hardly applicable, since it would then be the anteriormost mesothoracic sternite, instead of the posteriormost prothoracic sternite (as the name "poststernellum" would indicate). The relation of the spiracles to the thoracic sclerites, the mechanism of the thoracic spiracles, and similar topics will be discussed in a paper dealing with the respiratory system of the roach, and need not be further discussed here.

As is shown in Fig. 12, the pronotal plate or "pronotum" is divided into a disk or central portion labelled disc and a marginal region or limb labelled limb, whose lateral areas are called paranota. The ventral inflexed margins of the pronotum are closely applied to the dorsal surface of the pronotum (above) and the edges of these margins apparently exert a tension, resulting in the formation of faint lines such as those indicated by the dotted lines bordering the disk of the pronotum shown in Fig. 12. In the discal region, labelled disc, are several musclescars, or myocicatrices, etc., which need not be further discussed at this time, since they will be described in a paper dealing with the muscular system of the roach. The pronotal plate probably corresponds to the eunotum (or wing bearing plate) of the other thoracic segments, in which a prescutum, scutum and scutellum are secondarily demarked in the eunotum of the meso- and metathorax, but these areas are not demarked in the pronotum. The poorly chitinized and pigmented area labelled psl1 in Fig. 16 , probably represents the postscutellum of the other thoracic 
segments (in which the postscutellum is formed behind the eunotum or wing-bearing plate). The small anterior margin of the mesonotum bearing the label pm in Fig. 16 may be considered as a posterior portion of the prothorax, since, as Dr. Snodgrass points out, the phragmas represent the lines of demarcation between the segments dorsally, and the area $p m$ of the mesonotum (Fig. 16) lies in front of the phragmas (or internal structures for muscle attachment, whose location is indicated by the pits $p p t$ of Fig. 16) and should therefore be reckoned to the prothoracic region, although it is borne on the anterior margin of the mesonotum.

In the meso- and metanotal region, the wing bearing plate, or eunotum, is divided into the following regions. The anteriormost sclerite, or pretergite,prt of Fig. 16, is an ill-defined region bearing the phragmal pitts $p p t$ which mark the location of the internal ridges or phragmas $p h$ of Fig. 13, for example, and these phragmas or phragmal ridges delimit the segments dorsally, so that the anterior marginal region $p m$ of the pretergite being anterior to the phragmas, belongs to the segment in front, as was mentioned above. In the mesonotum of the roach (Fig. 16) the prealar sclerite pra becomes detached from the lateral region of the pretergite prt, while in the mesonotum of the mantid shown in Fig. 6, the region pra forms an incomplete prealar bridge, which is well developed in such insects as the Plecoptera, etc. In the metanotum of the roach (Fig. 16) the prealar sclerite pra does not become detached (as it does in the mesonotum) but it bears a pit like that labelled $p p$ in the prealar sclerite pra of the mesonotum. The anterior margins of the sclerites prt and pra apparently become involved in the formation of the postscutellum of the segment in front, when the postscutellum is enlarged through further chitinization and pigmentation of the "intersegmental" membrane to form the large postscutellar plate of other insects

The faintly demarked median region labelled $p s c$ in the mesonotum of the roach (Fig. 16) corresponds to the prescutum of the mantid shown in Fig. 6, and represents the second important area demarked in the eunotum (or wing-bearing plate). The regions labelled $p n 2$ and $p n 3$ in the meso- and metanotum 
of the roach (Fig. 16) are probably secondarily-formed areas demarked by a rather faint suture pns, with its corresponding internal ridge $e p n 2$ of Fig. 13. These structures are extremely faint in the metanotum (Fig. 16).

The scutellum of the mesothorax $s l 2$ is greatly elongated and extends to the prescutal area psc of Fig. 16. In the metathorax, however, the scutellum $s l 3$ is shorter and a suture-like structure $m d s$ of Fig. 16 connects it with the prescutal region. The scutellum sl2 (Fig. 16) is a demarked area of the eunotum bounded laterally by the scutellar sutures sls with their corresponding internl ridges etc., labelled esl2 in Fig. 13

Behind the scutellum sl2 (Fig. 16) is the posttergite pot, which is formed by a posterior fold, or reduplication, of the wing-bearing plate, or eunotum. Behind this are the postscutellar plates psl (Fig. 16), which encroach upon the membranous region, in other insects, and finally incorporate the marginal region $p m$, in front of the phragmal pits $p p t$, to form the large postscutellum of higher insects, in which the postscutellum may appear to bear the phragma. The postscutellum of the roach is but feebly developed and is represented by the small plates bearing the label psl in Fig. 16. These plates are formed behind the wing-bearing plate, or eunotum, whose post. erior margin is continuous with the posterior margin of the wing.

In the eunotum, or wing-bearing plate, the scutum $s c$ (Fig. 16) is very large and it occupies the greater part of the eunotum. It bears an anterior wing process, or suralare sur (which may be a lateral portion of the region prt in some insects), and a posterior wing process, or adanale ad (Figs. 16, 6 and 10), in front of which is an important incision $n i$, serving to divide the scutum into an anterior region and a posterior region, the latter being practically equivalent to the region called the parascutellum in other insects. The incomplete sutures extending mesad from the incision $n i$ in Fig. 16, correspond in a general way to the transscutal sutures, dividing the scutum into an anterior and posterior region in certain insects.

A tegular incision $t i$ of Fig. 6, usually separates the prealar sclerite pra from the suralar sclerite sur, and the tegula $\mathrm{tg}$ is located at the mouth of the incision in most insects (Figs. 6, 10, 
13, 16, etc.). The tegula $t g$ (Figs. 6 and 16) is probably formed by the deposition of chitin and pigment in the membrane near the tegular incision $t i$, but the parategula, or basicostale ptg 2 (Figs. 6 and 16), is probably a detached basal portion of the costal region (or vein) of the wing.

Behind the suralar sclerite sur of Figs. 6, 10, 16 etc., is the suralar incision si and the alar ossicle labelled $n$ in these figures, which is called the notale, or notopterale, is located in the neighborhood of the incision si. The alar ossicle $n$ appears to be a detached portion of the notum. It is prolonged anteriorly into a neck-like, slender portion, whose "head" abuts against the end of the sclerite scc. The sclerite $s c c$ is a demarked "head" of the subcostal vein, and is the dorsal portion of the subcostale $d$ (Figs. 1, 13, etc.) located on the under surface of the wing. The medialia, or median ossicles $a, b$ and $c$ of Figs. 6, 10, 16 etc., intervene between the ossicle $n$, and the base of the wingveins radius and media. The proximal mediale $a$, is separated from the ossicle $n$ by the cleft $n m$ of Fig. 16, and ossicle $a$ sends down a ventral prolongation $i a$ of Fig. 14, to form the ossicles labelled $i a$ in Fig. 1, which are located just above the alifer $o$ (the wing-bearing process of the pleuron). The incision in of Figs. 6 and 16 separates the ossicle $a$ from ossicle $b$, which is usually, closely associated with the ossicle $b a$ of Figs. 6, 10 and 16. The suture (or cleft) $i m$ of Figs. 6, 10 and 16, separates the intermediate median ossicle $b$ from the distal median ossicle $c$. Ossicle $c$, in turn, is separated from the head of the vein labelled $m c a$, by the suture labelled $m s$ in Figs. 16, 6 and 10.

The basanal ossicle $b a$ of Figs. 16, 6, 10 etc., usually articulates with the posterior notal wing process, or adanale $a d$, at one end, while at the other end, it is associated with the ossicle $a$, and is usually united more or less closely with ossicle $b$ (see also Fig. 14). The anale, or anal ossicle an of Figs. 6, 10 and 16, intervenes between ossicle $b a$ and the base of the anal region in the fore wing of the roach, mantid and termite here figured. Faint traces of a postbasanal ossicle may be seen behind the ossicle labelled $b a$, in the metanotum of the roach shown in Fig. 16.

In the fore wing of the roach shown in Fig. 16, the mantid 
shown in Fig. 8, and the termite shown in Fig. 10, the anal, or claval, area $a a$ of the tegmen (fore wing) is connected with the notum by a region called the alula, or jugalula $j a$ which may be involved in the formation of the jugum etc., of higher insects. An axillary ridge, or a crack-like rima po (Figs. 6 to 10), separates this region from the anal or claval region $a a$ (Figs. 6, 7, 8, $9,10,16$ etc. and the veins which are located behind this line of demarcation (i .e. such as those labelled $a x$ in Figs. 8, 9, etc.) should be referred to as the axillaries or axillary veins. The faintly chitinized and pigmented areas labelled $j u$ in Figs. 6, 10 and 16, are formed in the basal region of the alula; and the sclerite behind the metathoracic ossicle $b a$ of Fig. 16, may be associated with these areas of the fore wings. The sclerite pju of the hind wing of the roach (Fig. 16), however, seems to be formed behind the area containing the region $j u$ in the fore wing (Fig. 16), and is connected with a different portion of the notum by a narrow neck as is shown in Fig. 16. The relation of these parts to the calypteres of Diptera, etc., will be discussed in another paper.

In studying the fore wing of the roach I noticed a basal, ridge-like fold $b p$ and a deep "marsupium" or basal sinus $b s i$ (best seen after boiling the parts in caustic potash to spread them apart more readily), such as that shown in the tegmen (modified fore wing) figured in Fig. 16 These structions are very prominent, but have been apparently overlooked before, although they occur in a great many of the insects descended from the ancestral types included in the common Protorthop teron-Protoblattid stem-e. g. in such insects as those shown in Figs. 11, 16, 7, 8, 9, and 10. I do not find this basal fold and sinus in such insects as the ephemerids and Odonata which cannot lay their wings back along the top of the abdomen in repose, while the descendants of the groups which can do this (see division of insects into two groups on this basis in Vol. 16 p. 33 of the Journal of Ent. and Zoology for 1924, or papers in the Transactions of the Amer. Ent. Society,,LII, 1926,p. 239) show distinct traces of the fold and sinus (as I have also pointed out in the Bull. Brooklyn Ent. Soc., 1927, XXII, p. 1) so that the presence of these structures is of considerable importance 
from the standpoint of phylogeny, and these structures likewise serve as landmarks in determining the location of certain veins, areas etc., of the wing. The basal fold $b p$ and pocket-like sinus $b s i$ are very prominent in the fore wings of roaches, termites, the Hemiptera with coriaceous fore wings, etc., and it is very probable that these structures were developed in order to facilitate the folding back of the fore wings, when these are laid along the top of the abdomen in repose (see Bull. Brooklyn Ent. Soc., 1927). I shall again refer to these structures in a paper dealing with the basal region of the wings of insects in general, so that it is not necessary to discuss the matter further at this time.

As was mentioned above, a postanal, or postclaval ridge (or in some cases a rima, or crack-like line) labelled po in Figs. 6, 7, $8,9,10$ and 16, demarks the axillary, or alular region, from the anal, or claval region of the fore wings. A preanal, or preclaval rima $c l$ demarks the anal area of the wing from the median region of the wing, and the rima $c l$ may be regarded as a "rima dividens" paralleling the "vena dividens" described by Comstock and others, in this region of the wing. A median rima, in front of the rima labelled $c l$ in Figs. 10 and 16, demarks the median area of the wing from the radial area, in some insects, and a costal area $c a$ of Fig. 16, is frequently demarked by the subcostal vein $S c$ in roaches, termites etc.

On the under side of the fore wing of the roach, as shown in Fig. 2, there is an important ventral ridge, the subcostal crista or plica scr, extending along the subcostal vein, and the condition exhibited in this region of the fore wing of the roach is of considerable interest from the standpoint of phylogeny, since the tegmen (fore wing) of the roach offers a very suitable startingpoint for tracing the modifications in this area of the elytra of beetles and the fore wings of other insects descended from roach-like forebears in the common Protorthopteran-Protoblattid stem.

When the fore wing of the roach is laid back in repose, it assumes the position shown in Fig. 2; and a protuberance $m$ of the epimeron $\mathrm{em} 2$ fits into a cavity in which the sclerite $d$ at the base of the subcostal vein (or subcostal ridge scr) is located. The subcostal ridge scr lies above, and mesal to, the projecting 
areas of the epimeron $e m 2$ and meron $m e 2$ in repose, and the subcostal ridge may have been developed in connection with holding the wing in place when at rest. When the hind wings are folded back in repose, the sclerite $x$ of Fig. 4, projects into a pocket between the structures labelled ptg 3 and $d$ in Fig. 4, and the costal edge of the hind wing lies above the process $m$ of the epimeron em 3. Much of the anterior region of the wing lies on top of the area labelled $w$ in Fig. 3, and this area was apparently developed in connection with holding the wing up in repose.

A more detailed description of the folding of the wings, the basal structures of the wings, the areas of the wings, the interpretation of the veins (indicated in Fig. 16), and the mechanism of flight, etc., will be given in a paper dealing with the thoracic appendages of the roach, and need not be further discussed here.

\section{Berlesi}

\section{Literature Cited}

1909. Gli Insetti.

Crampton

1909-1926. Thorax of Insects, Proc. Acad. Nat. Sciences, 1909, p. 3; Same Subject, Ent. News, 1914, 25, p. 15; Typical Segment, Zool. Anzeiger, 1914, XLIV, p. 56; Legs of Insects, Zool. Jahrb., 1915, 39, p. 1; Nature of Cervical Sclerites, Annals Ent. Soc. America, 1917, 10, p. 187; Terga and Wing Bases of Orthopteroids, Psyche, 1918, 25, p. 4; Thoracic Sclerites of Immature Insects, Proc. Ent. Soc. Washington, 1918, p. 39; Parts of an Insect's Leg, Can. Ent., 1923, LV, p. 126; Head and Abdomen of Roach, Psyche, 1925, XXXII, p. 195; Neck and Prothorax of Insects, Trans. Amer. Ent. Soc., 1926, LII, p. 199, etc. Miall and Denny

1886. The Structure and Life History of the Cockroach.

Snodgrass

1908. A Comparative Study of the Thorax in Orthoptera, etc. Proc. Ent. Soc. Washington, IX.

1909. The Thorax of Insects, Proc. U. S. Nat. Museum, XXXVI, p. 511.

1909. The Thoracic Tergum of Insects, Ent. News, XX, p. 97. 


\section{Abbreviations}

\begin{tabular}{|c|c|}
\hline $\begin{array}{l}\text { Proximal median ossicle (prox- } \\
\text { imediale) }\end{array}$ & Prepectal impress \\
\hline Analarea or clavalarea & Intermediate cervical plate (in- \\
\hline Antecoxale (later & tercervicale) \\
\hline Adanal process (adanale) & Intertergite \\
\hline Anepisternal incision & Intermediate surure or incision \\
\hline Anepisternum & Submedian suture or incision \\
\hline Anal ossicle (anale) & Intersternite \\
\hline Apodeme of endopleuron & Alula (jugalula) \\
\hline Antetrochantin & Jugale \\
\hline Axillary vein & Laterocervicale \\
\hline $\begin{array}{l}\text { ate median ossicle } \\
\text { ediale) }\end{array}$ & $\operatorname{limb}_{M}$ \\
\hline sicle (basanale) & Epi \\
\hline Bas & ma. \\
\hline incision $\mathrm{o}$ & mc. \\
\hline or hacosricta & Media (mediacaput) \\
\hline ite or bas & me.. \\
\hline Bas & mds \\
\hline Basi & mr.. \\
\hline median ossicle (distime- & $\begin{array}{l}\text { ms... } \\
\text { n.... }\end{array}$ \\
\hline rea (embolium) & incision \\
\hline Co: & uture \\
\hline $\mathrm{Ce}_{1}$ & o. \\
\hline ens (preclavorima) & occ. \\
\hline Cox & ature \\
\hline $\mathrm{Cub}$ & pac \\
\hline Cox & 1 tendon \\
\hline (subcostale) & pc. \\
\hline & pes. \\
\hline Dis & pgu. \\
\hline & lge ar \\
\hline En & pju. \\
\hline En & inale \\
\hline $\begin{array}{l}\text { ral cervical plate } \\
\text { le) }\end{array}$ & m suture \\
\hline xal region (eucoxa) & $\begin{array}{l}\text { po..... Posterior rima (postrima) or } \\
\text { ridge }\end{array}$ \\
\hline Epir & rvicale \\
\hline dopapilla & pot.. \\
\hline Endo & pp. \\
\hline m & pit (phragma \\
\hline Episternum & Precervicale \\
\hline re & pra. \\
\hline En & \\
\hline (endotergite) & Pleural suture \\
\hline En & \\
\hline coxa for muscle & psl. \\
\hline (2) & pt.... \\
\hline furcasternum & $\begin{array}{l}\text { ptg... } \\
\text { ptn.. }\end{array}$ \\
\hline furca & \\
\hline coxal & pisternal suture \\
\hline
\end{tabular}


s.......Preepisternal suture

sa...... Subalare

san.... . Subanale

sb...... Subcostale

Sc..... Subcostal vein

sc...... Scutum

scc.... Subcostal head (subcostacaput)

scr.... Subcostal crista (subcrista)

si...... Suralar incision

sl...... Scutellum

sls..... Scutellar suture

sp...... Spinal pit (spinacava)

spi.... Spina or monapophysis ss...... Spinasternite

st...... Spiracle

su...... Subspiraculare

sur..... Suralare

t....... Prepleurite

tg..... Tegula

ti..... Tegular incision

tn...... Trochantin

ttn..... Trochantinal tendon

u...... Anterior basalare

v...... Subcostal incision

w...... Wing imprint on epimeron

x...... Posterior basalare

Explanation of Plates I, II, III.

Fig. 1. Ventral view of sternal and pleural region of the thorax of the roach, spread out as though lying in one plane.

Fig. 2. Ventral view of the mesothoracic wing-base, pleural region and meral region of the leg of the roach.

Fig. 3. Ventral view of basal region of the metathoracic wing folded back in repose.

Fig. 4. Ventral view of metapleural region and base of hind wing spread out slightly.

Fig. 5. Internal processes of the sternal and pleural region of the thorax of the roach seen from above (i. e. from within).

Fig. 6. Lateral portion of the mesonotum and the base of the fore wing (extended) of the mantid Mantoides.

Fig. 7. Postero-basal region of the hemielytron of a Pentatomid.

Fig. 8. Postero-basal region of the fore wing of Panorpa (seen from above).

Fig. 9. Postero-basal region of fore wing of the sawfly Pteronidia.

Fig. 10. Basal region of the fore wing of the termite Mastotermes.

Fig. 11. Basal region of the fore wing of the beetle Calopteron.

Fig. 12. Pronotal plate of the roach (dorsal view)

Fig. 13. Mesonotum of the roach seen from within.

Fig. 14. Lateral portion of metanotum and wing base of the roach seen from within.

Fig. 15. Mid-dorsal region of the neck of the roach seen from within.

Fig. 16. Dorsal view of meso- and metanotum, with basal regions of the wings of the roach. 


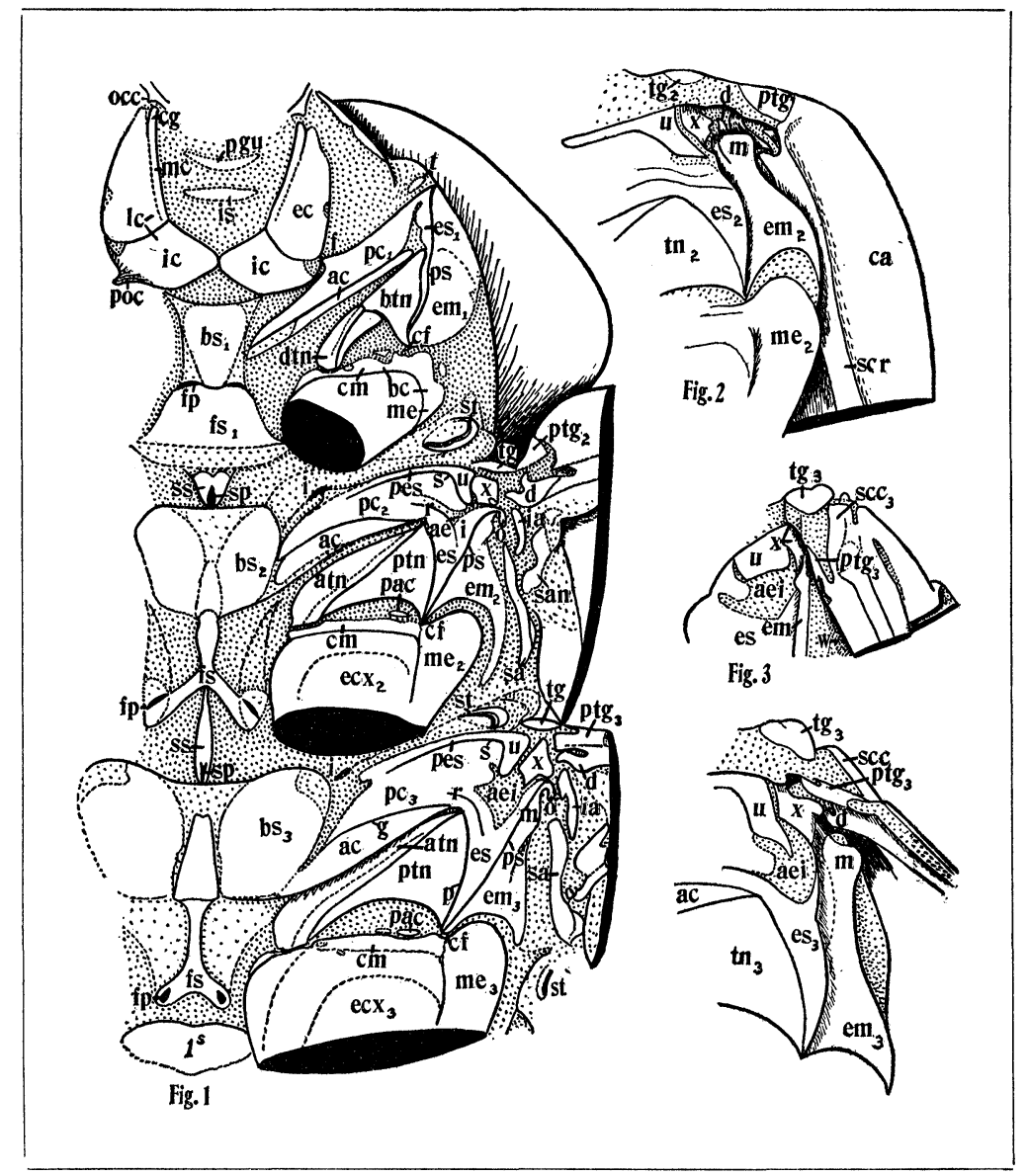

CRAMPTON-PERIPLANETA AMERICANA. 


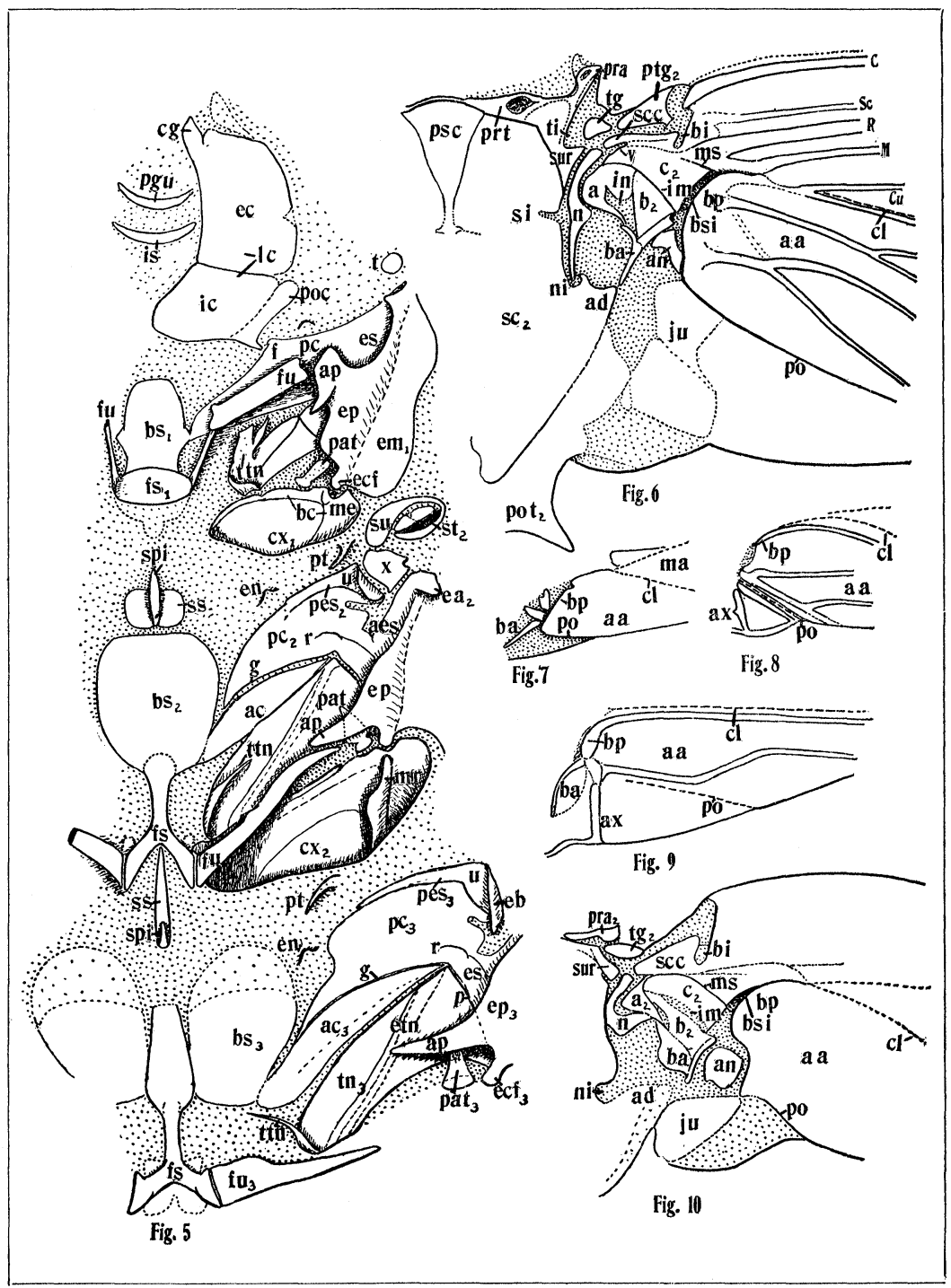

CRAMPTON-PERIPLANETA AMERICANA. 


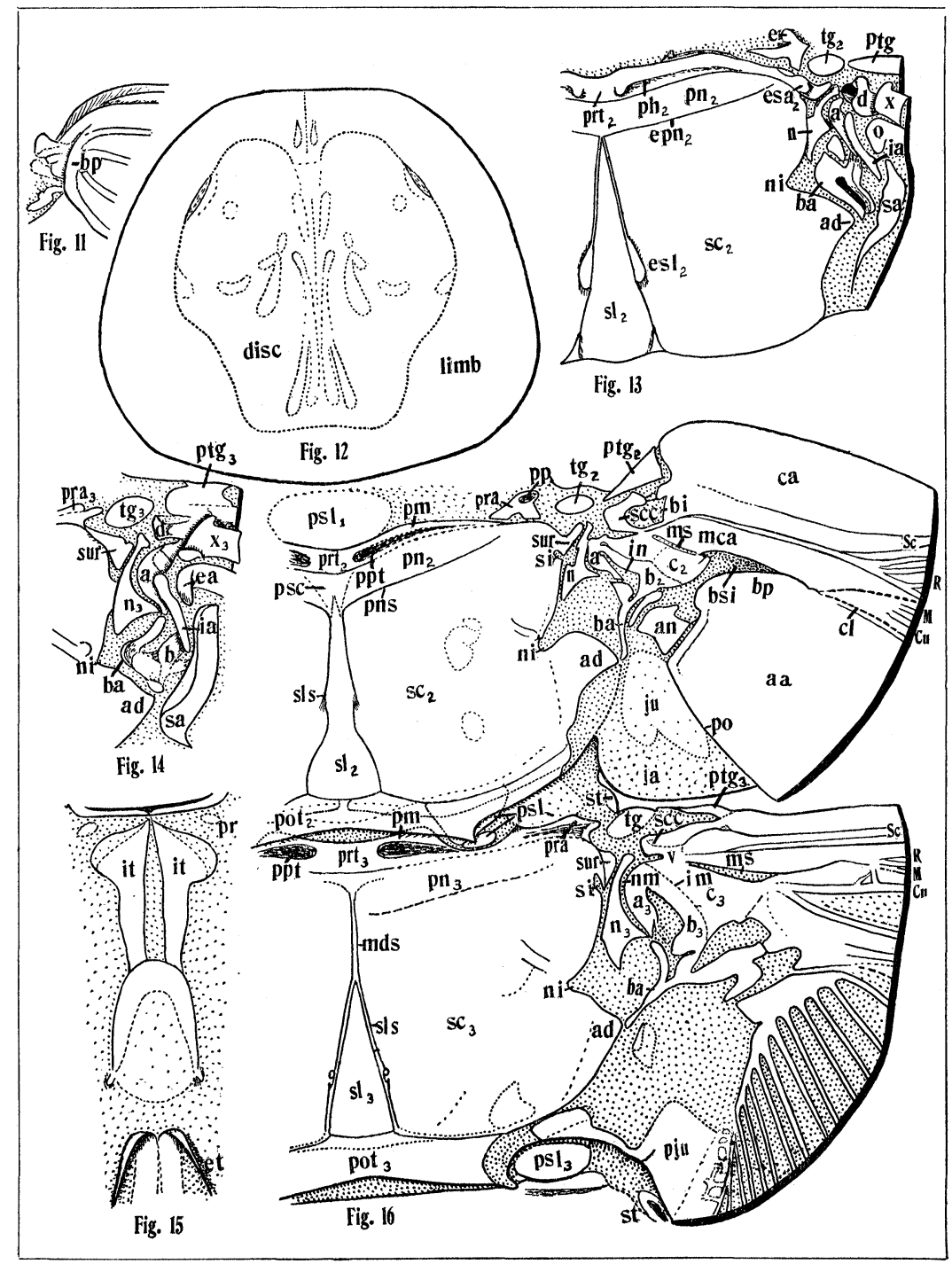

CRAMPTON-PERIPLANETA AMERICANA. 

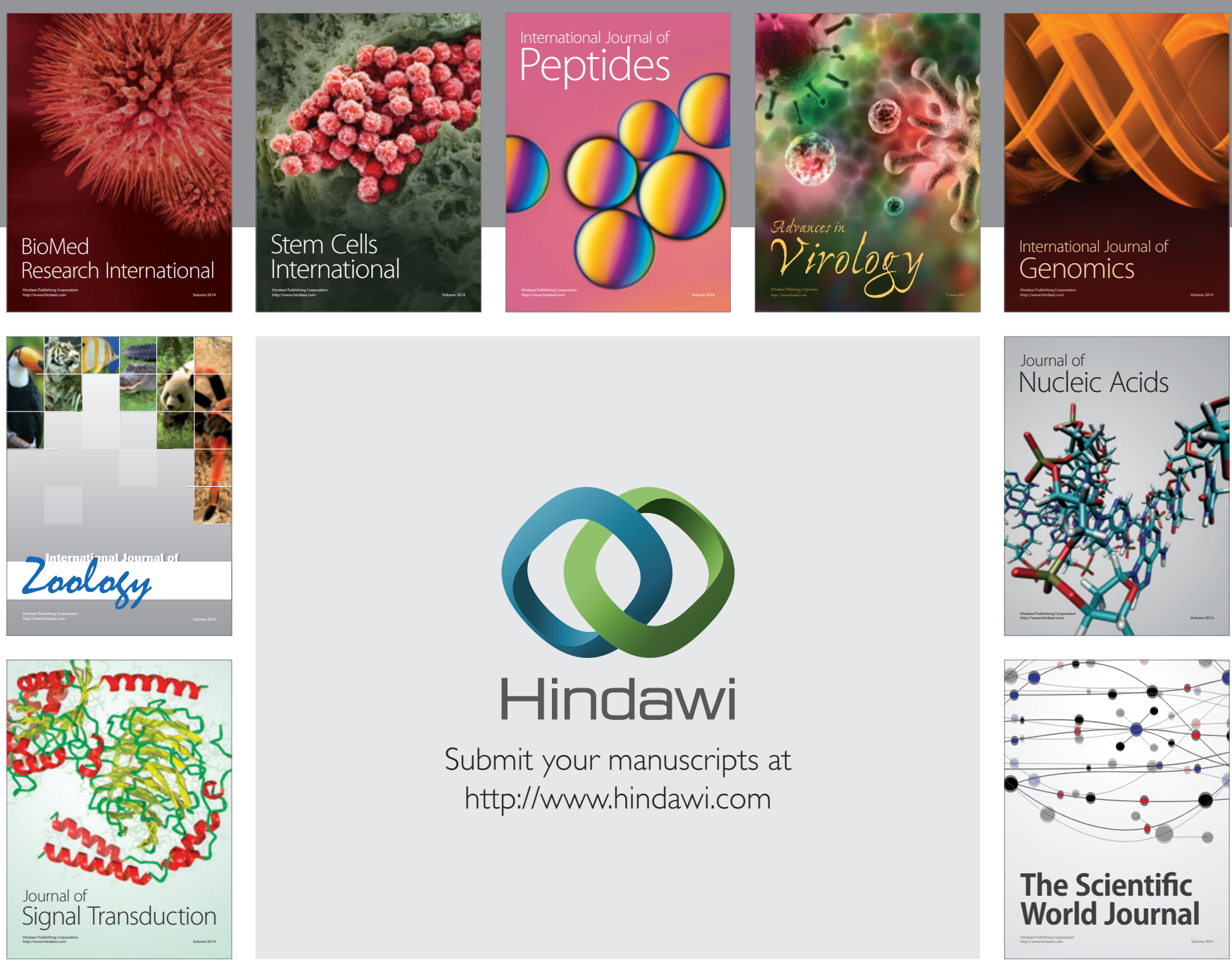

Submit your manuscripts at

http://www.hindawi.com
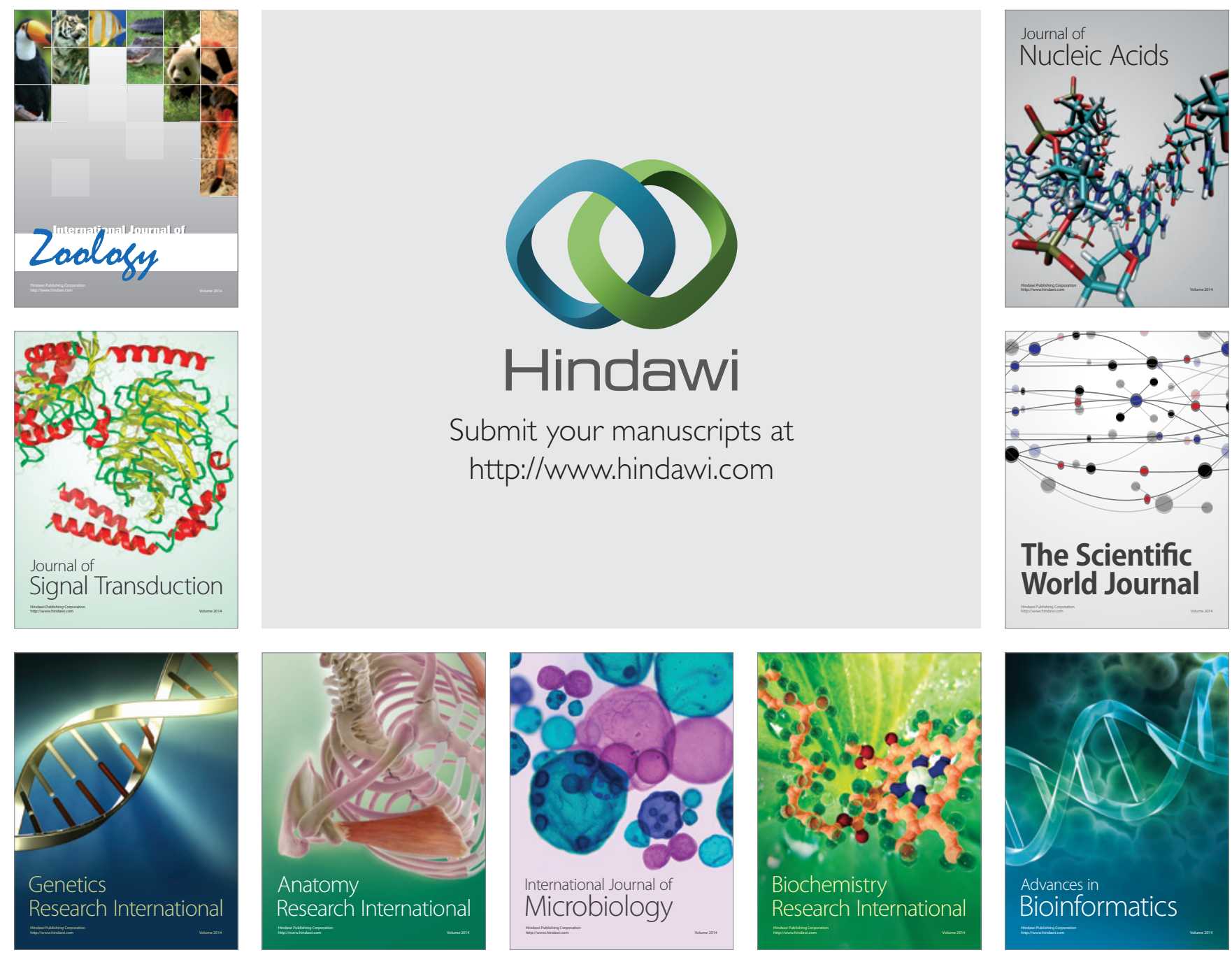

The Scientific World Journal
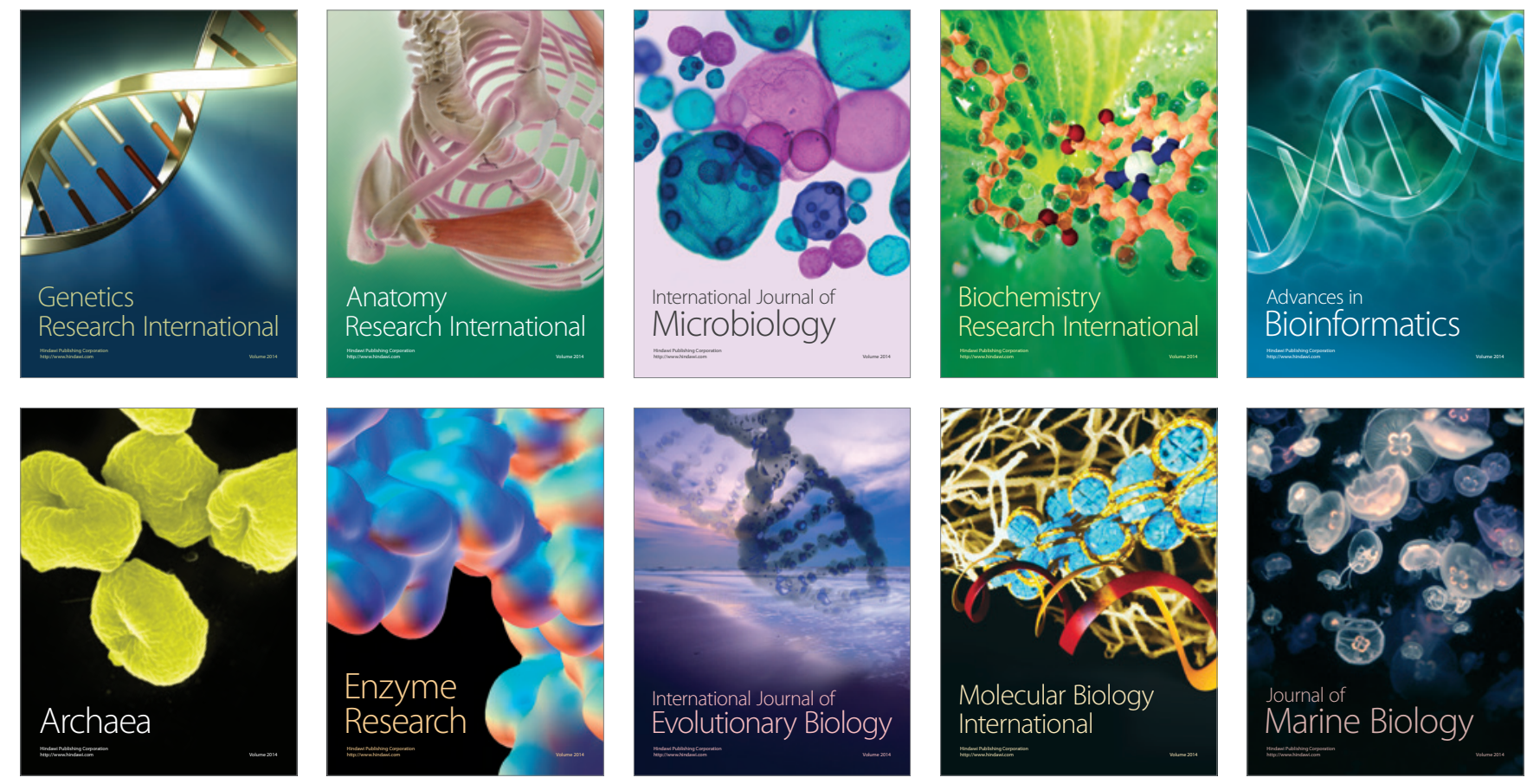